\title{
Study on comprehensive measurement of urbanization level in
}

\section{Changzhou}

\author{
Hanbing Jin ${ }^{1, a}$ and Lanping Feng ${ }^{1, b}$ and Lu Meng ${ }^{2, c}$ \\ ${ }^{1}$ Business Administration School of Hohai University, 213022 Changzhou, China \\ ${ }^{2}$ East China University of Science and Technology, 200237 Shanghai, China \\ a1538965882@qq.com, b6412118@qq.com, 466865487@qq.com
}

Keywords: urbanization; comprehensive index; Changzhou

Abstract. According to the connotation of urbanization, this paper constructs comprehensive evaluation index system of regional urbanization level from four aspects that population urbanization, economic urbanization, spatial urbanization and social urbanization, and uses the method of entropy to make comprehensive analysis of Changzhou urbanization level from 2003 to 2013. The result shows that the most prominent feature of Changzhou urbanization is spatial characteristics; Rapid development of social urbanization has the trend of catch up from behind in recent years; the development of economic urbanization is relatively stable; Population urbanization tends to be stable after a long period of development.

\section{Introduction}

Urbanization refers to the process of the population to urban areas and rural areas into urban areas, which is a social and economic transformation process involving population, economy, society, culture and so on ${ }^{[1]}$. The relevant research on the level of urbanization is not only the basis of the national or regional development policy ${ }^{[2]}$, but also has been the focus of academic circles. The academic circles put forward single index method and composite index method to measure the level of urbanization ${ }^{[3 \sim 5]}$. Single can only reflects the results of a certain amount of urbanization, while the composite index can reflect the development level of regional urbanization comprehensively and completely so it is increasingly accepted by academia and local government departments.

As a modern equipment manufacturing city, Changzhou developed rapidly in recent years, it has the demonstration significance to study the urbanization comprehensive level of industry led area that urbanization has fully raised space.

\section{Comprehensive measurement of urbanization level in Changzhou}

Index system construction and weights determination. On the basis of systematic, representative, effective, scientific and comparable principles, this paper selects 16 indicators from four aspects, that is: population urbanization, economic urbanization, spatial urbanization and social urbanization, to construct the corresponding index system, strives for a more comprehensive and accurate reflection of the level of urbanization development.

This paper uses entropy method to determine the weights, it can clearly reflect the utility value of index information entropy ${ }^{[6]}$, and the weights of the index will be more objective and scientific ${ }^{[7]}$.

According to the entropy method and the data obtained, the calculation results are as follows:

The weight of population urbanization, economic urbanization, spatial urbanization and social 
urbanization are respectively $0.252,0.244,0.261$ and 0.242 .

In the subsystem of population urbanization, the indexes and the corresponding weights are urban population proportion(0.0772), urban population size(0.074), second industry practitioners proportion (0.0374) and tertiary industry practitioners proportion $(0.0637)$; The indexes and the corresponding weights of population urbanization are per capita $\operatorname{GDP}(0.0678)$, per capita gross industrial output value(0.0634), second industrial output value accounted for GDP(0.0519) and tertiary industry output value accounted for $\operatorname{GDP}(0.0611)$; In the subsystem of population urbanization, they are built-up area green coverage rate (0.044), built-up area(0.0781), per capita possession of road (0.0718) and per capita park green area(0.0677); And in the subsystem of population urbanization, they are total retail sales of social consumer goods( 0.0667$)$, per capita disposable income of urban residents(0.063), per capita posts and telecommunications business(0.0566) and per million people with doctors' number(0.0557).

Comprehensive index model. According to the index system and the data obtained, the level of urbanization and urban ecosystem health level is measured. In this paper, the corresponding results are obtained by using the comprehensive index model.

$$
Y_{j}=\sum_{i=1}^{i} x_{i} w_{i}
$$

In the formula (1), $Y_{i}$ represents the composite index, $x_{i}$ is the standard value of the evaluation index, and $w_{i}$ is the weight of the evaluation index.

This paper chooses the common individual index of urbanization, urban population proportion, as a reference for the comprehensive level of Urbanization, and makes a comparative analysis of the comprehensive index of the sub system, as shown in Fig. 1; Calculates the index of urbanization and the growth rate of the index of the sub system, and sums up their respective development rules and trends, as shown in Table 1.

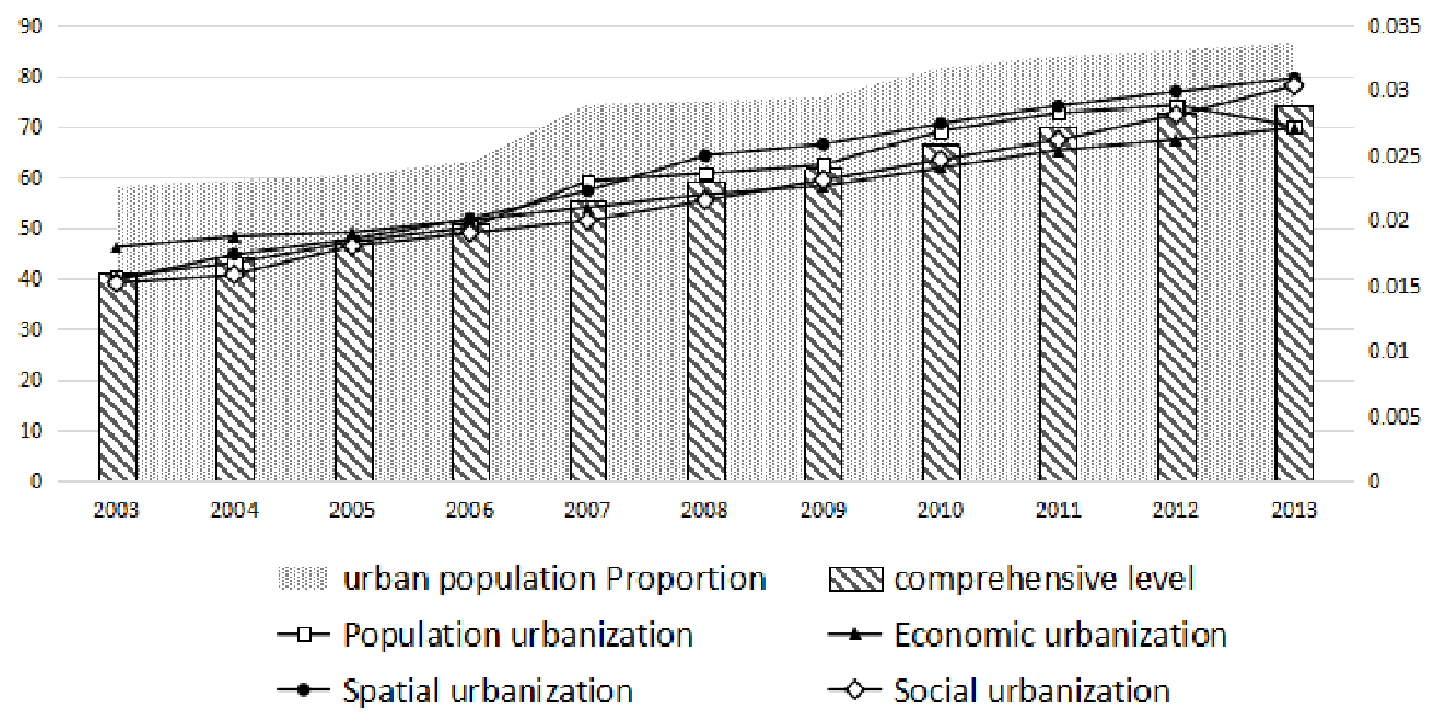

Fig. 1: Evolution process of urban population proportion, urbanization comprehensive level and subsystem 


\section{The urbanization level development of Changzhou and its evolution}

Main index contribution analysis. According to the weights calculated above, we can see that on the level of subsystem's weight, Changzhou urbanization is mainly reflected in the urbanization of space and population. From the perspective of the weight of specific evaluation indexes, built-up area is the main factor that affects the evolution of urbanization in Changzhou. In addition, weights of per capita GDP, per capita industrial output value, urban residents per capita disposable income and others have a greater impact on the development of urbanization too. Other index weights are small and their impacts of the urbanization are relatively weak.

Table 1: Scores and development rates of the comprehensive level of urbanization and the score of each subsystem in Changzhou

\begin{tabular}{|c|c|c|c|c|c|c|c|c|c|c|}
\hline & \multicolumn{2}{|c|}{$\begin{array}{l}\text { Comprehensive } \\
\text { level }\end{array}$} & \multicolumn{2}{|c|}{$\begin{array}{l}\text { Population } \\
\text { urbanization }\end{array}$} & \multicolumn{2}{|c|}{$\begin{array}{l}\text { Economic } \\
\text { Urbanization }\end{array}$} & \multicolumn{2}{|c|}{$\begin{array}{c}\text { Spatial } \\
\text { Urbanization }\end{array}$} & \multicolumn{2}{|c|}{$\begin{array}{l}\text { Social } \\
\text { urbanization }\end{array}$} \\
\hline & Score & $\begin{array}{l}\text { Chain } \\
\text { rate }\end{array}$ & & $\begin{array}{l}\text { Chain } \\
\text { rate }\end{array}$ & & $\begin{array}{l}\text { Chain } \\
\text { rate }\end{array}$ & & $\begin{array}{l}\text { Chain } \\
\text { rate }\end{array}$ & & $\begin{array}{l}\text { Chain } \\
\text { rate }\end{array}$ \\
\hline & & & & & & & & & & \\
\hline 004 & & 1.068 & & & & & & & & \\
\hline 2005 & & & & & & & & & & 1.1390 \\
\hline 2006 & & 1.0649 & & 10610 & & & & & & \\
\hline 2007 & & 1.0964 & & & & & & & & 1.0484 \\
\hline 2008 & & & & & & & & & & 1.0709 \\
\hline 2009 & 0.0240 & 1.0390 & & 1.0272 & & & 00250 & & & 1.0729 \\
\hline & & & & & & & & & & 1.0660 \\
\hline 2011 & 0.0272 & 1.0543 & & & & & & & & 1.0624 \\
\hline & & 1.0404 & & & & & & & & 1.0726 \\
\hline 2013 & 0.0289 & 1.0212 & 0.0272 & 0.9425 & 0.0271 & 1.0339 & 0.0309 & 1.0338 & 0.0303 & 1.0806 \\
\hline
\end{tabular}

Analysis on the trend of urbanization in Changzhou. Figure 1 and table 1 show that in these 11 years, the level of urbanization in Changzhou continues to improve, especially in the 2003 to 2010 years, the level of urbanization is rapidly increasing, and the speed of development has slowed down since 2010. In addition, this paper selects the index of urban population proportion as a reference. This index developed rapidly during the period of 2003 2010, and the development speed is also beginning to slow down in 2010 2013. Besides, based on this individual index, the urbanization process is roughly divided into three stages: the initial stage (urbanization level is lower than $30 \%$ ), the middle period (30\% to $70 \%$ ), and the late urbanization (higher than $70 \%$ ). According to this standard, Changzhou has experienced a development from high speed to low speed in 2003 2013.

All of the above shows that in 2010, the overall level of urbanization in Changzhou has changed. On the one hand, it shows that the development of urbanization has entered a bottleneck period after a long period of rapid development. On the other hand, the development mode of Changzhou's processing trade is affected by the rising cost of production and the strong pressure from the adjustment of the national policy, which affects the level of urbanization.

Analysis on the evolution characteristics of urbanization subsystem. The level of each subsystem of the urbanization in Changzhou has been continuously improved, and it has been shown to have different evolution characteristics. Spatial urbanization is the most prominent feature 
in Changzhou. The spatial urbanization index has been in a leading position after 2007, and since 2010 , the growth rate has declined year by year.

In recent years, Social urbanization level has the trend to catch up from behind. After 2008, the social urbanization index maintained a high growth rate. This is due to accelerate the pace of urban construction process; Changzhou has focused on the implementation of the urban transport, environmental improvement and livelihood security upgrade and other projects.

The level of economic urbanization is relatively stable. In Changzhou, the second industry changes in a small range, although the proportion has decreased, it still occupies dominant position, and is the main driving force of economic development in Changzhou.

The speed of population urbanization development tends to be stable. The increment speed of urban population proportion is slowing down and the urban population tends to be saturated.

\section{Countermeasures and suggestions}

Population urbanization is mainly reflected in the expansion of urban population proportion. After a long period of development, urban population tends to saturation in Changzhou, so it puts forward higher requirements in other areas to improve the urbanization level in Changzhou.

First of all, it can be seen from the development status of economic urbanization that it is still dominated by secondary industry in Changzhou. Therefore, the successful implementation of the heavy industry transformation and capacity transfer will determine the long-term development direction and trend of the industry and economy in Changzhou. From now on, on the one hand, it is necessary to increase investment in high-tech industries such as pharmaceutical manufacturing industry, intelligent equipment manufacturing industry; On the other hand, it need to actively play the role of financial and financial linkage, and support the development of emerging industries, and thus continue to optimize the economic structure, and improve the industrial level. Secondly, it should be oriented by the economic and industrial structure adjustment and upgrading in Changzhou, to increase the employment and improve the employment ability of urban residents. In addition, we should further expand the urban green coverage area, so to optimize the urban space distribution. Finally, we should pay attention to the per capita posts and telecommunications business volume indicators, and according to the characteristics of the postal industry, find the node and the way of the integration of the postal and Internet, and promote the transformation and upgrading of Posts and telecommunications business, so as to improve the level of urbanization and the quality of life and convenience of the people.

\section{Conclusions and discussion}

This paper used entropy method to measure the comprehensive development of Changzhou city. The research result shows that in 2003 2013, the urbanization level of Changzhou continues to improve; the most prominent feature of Changzhou urbanization is spatial urbanization; Rapid development of social urbanization advanced shoulder to shoulder with spatial urbanization in recent years; Economic urbanization development is relatively stable, and the tertiary industry is growing, and its contribution to the economic development of Changzhou has become increasingly prominent; Population urbanization is mainly reflected in the expansion of the urban population proportion, after a long period of development, population urbanization process has become stable. 
This paper only analyzes the level of urbanization in Changzhou and the development level of each subsystem, and does not discusses the interaction intensity and coordination degree between each subsystem, and it will be explored in future study.

\section{Acknowledgements}

The research work was supported by the Fundamental Research Funds for the Central Universities(Grant No. 2013B09314), P.R. China, and the Research Innovation Program for College Graduates of Jiangsu Province (Grant No. KYLX15_0523).

\section{Reference}

[1] Mingxing Chen, Dadao Lu, Hua Zhang: Acta Geographica Sinica. 04, 387-398(2009)

[2] Xiangjun $\mathrm{Ou}$, Feng Zhen, Yongdong Qin, Lingzi Zhu and Hong Wu: Geographical Research, 05, 993-1002(2008)

[3] Tongsheng Zhang, Jinshe Liang and Jinping Song: Urban Studies, 02, 36-41(2002)

[4] Hezhi Dai, Zhaode Liu: URBAN PROBLEMS, 04,21-24(1998)

[5] Li Zhang: Habitat International. 10,1016-1034(2008)

[6] Youhua Ye, Fangfang Sun, Yuan Zhang, Tao Huang, Xiaoyan Lin and Li Chen: Ecology and Environmental Sciences. 12,1996-2002(2014)

[7] Wenhui Xie: Journal of Tsinghua University (Philosophy and Social Science). 14, 2(1999) 